\title{
Shared Air: A Renewed Focus on Ventilation for the Prevention of Tuberculosis Transmission
}

\section{Eugene T. Richardson ${ }^{1,2,3 *}$, Carl D. Morrow ${ }^{3}$, Darryl B. Kalil ${ }^{3}$, Linda-Gail Bekker ${ }^{3}$, Robin Wood ${ }^{3}$}

1 Division of Infectious Diseases and Geographic Medicine, Stanford University School of Medicine, Stanford, California, United States of America, 2 Department of Anthropology, Stanford University, Stanford, California, United States of America, 3 Desmond Tutu HIV Centre, Institute of Infectious Diseases and Molecular Medicine, University of Cape Town, Cape Town, Republic of South Africa

\begin{abstract}
Background: Despite an improvement in the overall TB cure rate from 40-74\% between 1995 and 2011, TB incidence in South Africa continues to increase. The epidemic is notably disquieting in schools because the vulnerable population is compelled to be present. Older learners (age 15-19) are at particular risk given a smear-positive rate of 427 per 100,000 per year and the significant amount of time they spend indoors. High schools are therefore important locations for potential TB infection and thus prevention efforts.

Methods and Findings: Using portable carbon dioxide monitors, we measured $\mathrm{CO}_{2}$ in classrooms under non-steady state conditions. The threshold for tuberculosis transmission was estimated using a carbon dioxide-based risk equation. We determined a critical rebreathed fraction of carbon dioxide $\left(\bar{f}_{c}\right)$ of $1 \cdot 6 \%$, which correlates with an indoor $\mathrm{CO}_{2}$ concentration of $1000 \mathrm{ppm}$. These values correspond with a ventilation rate of $8.6 \mathrm{l} / \mathrm{s}$ per person or 12 air exchanges per hour (ACH) for standard classrooms of $180 \mathrm{~m}^{3}$.

Conclusions: Given the high smear positive rate of high-school adolescents in South Africa, the proposal to achieve $\mathrm{CO}_{2}$ levels of $1000 \mathrm{ppm}$ through natural ventilation (in the amount $12 \mathrm{ACH}$ ) will not only help achieve WHO guidelines for providing children with healthy indoor environments, it will also provide a low-cost intervention for helping control the TB epidemic in areas of high prevalence.
\end{abstract}

Citation: Richardson ET, Morrow CD, Kalil DB, Bekker L-G, Wood R (2014) Shared Air: A Renewed Focus on Ventilation for the Prevention of Tuberculosis Transmission. PLoS ONE 9(5): e96334. doi:10.1371/journal.pone.0096334

Editor: Steven J. Drews, University of Calgary \& ProvLab Alberta, Canada

Received January 15, 2014; Accepted April 7, 2014; Published May 7, 2014

Copyright: (c) 2014 Richardson et al. This is an open-access article distributed under the terms of the Creative Commons Attribution License, which permits unrestricted use, distribution, and reproduction in any medium, provided the original author and source are credited.

Funding: ETR was funded by an Advanced Residency Training at Stanford fellowship, a Stanford Graduate Fellowship in Science and Engineering, and an Epidemiology of Emerging Infections and Bioterrorism training grant (NIAID: T32 AI052073). CDM and RW were funded by the International Epidemiologic Database to Evaluate Aids (NIAID: 5U01AI069924-02); Cost-Effectiveness of Preventing AIDS Complications (CEPAC) (NIH: 5R01AI058736-02); Cape Town Clinical Trials (CT-CTU) for HIV/AIDS Prevention and Treatment (NIH: 5 U01 Al069519-02); and Novel Methods to Inform HIV/TB Clinical Trial Development (NIH: 5R01A1093269-02). The funders had no role in study design, data collection and analysis, decision to publish, or preparation of the manuscript.

Competing Interests: The authors have declared that no competing interests exist.

*E-mail: etr@stanford.edu

\section{Introduction}

Once the infectious origin of tuberculosis was discovered by Koch in 1882, schemes for improving indoor ventilation spread across the industrialized world [1]; such plans were associated with dramatic declines in TB incidence [2]. South Africa, however, currently has tuberculosis notification rates similar to those reported in $19^{\text {th }}$ century industrializing nations [3]. Despite successful TB case identification and treatment programs, the country had an incidence greater than 1,000 per 100,000 people in 2012 [4]. This high incidence is not fully explained by HIV, as it was increasing prior to the start of the South African HIV epidemic in 1990 (see Figure 1) [5].

Many South African communities have yet to benefit from the campaign for healthy indoor environments found in high-income countries. And while the post-apartheid government in South Africa has done an excellent job formalizing 206 of the 2,700 informal settlements countrywide [6], a substantial number of South Africans still live in the equivalent of the $19^{\text {th }}$ century industrial tenement housing described by Marx and Engels [7].
Thus, a plausible explanation for the high prevalence is the continued existence of crowded, poorly ventilated indoor environments.

In 2012, young people aged 15-24 represented $17 \cdot 2 \%$ of all smear-positive cases in South Africa. Despite an improvement in the overall TB cure rate from 40-74\% between 1995 and 2011, TB incidence continues to increase [4]. The epidemic is notably disquieting in schools because - not unlike prisons [8]- the vulnerable population is compelled to be present. Older learners (age 15-19) are at particular risk given a smear-positive rate of 427 per $100,000[4,9]$ of their peers and the significant amount of time they spend indoors at school [10]. High schools are therefore important locations for potential TB infection and thus appropriate targets for prevention efforts.

The force of infection for tuberculosis in Cape Town has been calculated to be at least 6\% per annum in people aged 15-19 [11]. The number of individuals infected by each case (effective contact number) is determined by the ratio of the force of infection $(6 \%)$ and the prevalence of infectious TB cases $(427 / 100,000)$. For high school students in Cape Town, the calculated effective contact 


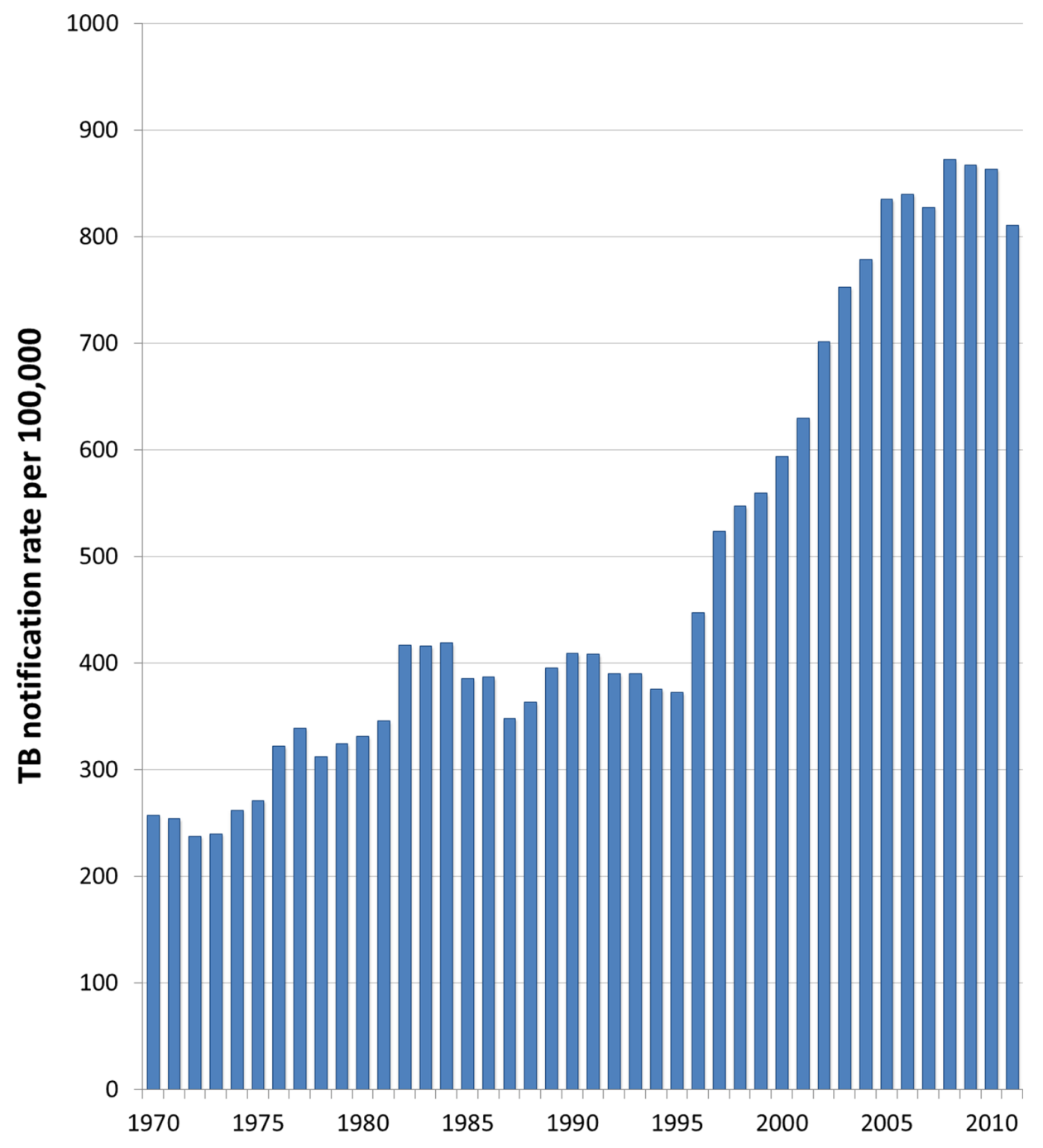

Figure 1. TB Notification Rates for Cape Town, 1970-2011 [5]. doi:10.1371/journal.pone.0096334.g001

number per case is 14. Effective TB control is achieved when the effective contact number is lower than the number of individuals who can be expected to develop infectious pulmonary TB over a lifetime. Thus, the effective contact number per case must be reduced to $<14$ to decrease the current TB burden.

Re-circulated indoor air has long been recognized as a mechanism for infectious disease transmission [12]. By measuring carbon dioxide levels in classrooms, one can estimate probabilities of TB transmission using the equation developed by Rudnick and Milton (see Methods):

Exhaled breath is the vehicle for release of airborne infectious particles. Exhaled breath contains almost 40,000 ppm of $\mathrm{CO}_{2}$ compared with approximately $350 \mathrm{ppm}$ [currently $400 \mathrm{ppm}$ due to anthropogenic global change] in outdoor air [13].

Their calculation incorporates $\mathrm{CO}_{2}$ as a surrogate for exhaled breath, thereby addressing two key limitations of the Wells-Riley equation [14] on which it was based. First, the Rudnick-Milton adaptation does not require the assumption of steady-state conditions. Second, it assumes the loss of infectious particles to settling, filtration, and loss of viability is negligible compared to that removed by ventilation [13].
Recent studies utilize the Wells-Riley equation to determine ventilation recommendations for $\mathrm{TB}$ prevention but are based on the assumption of steady state conditions $[15,16]$. We believe this is the first publication to date to use the Rudnick-Milton equation to determine ventilation recommendations for the transmission of tuberculosis under non-steady state conditions in schools.

\section{Methods}

\section{Ethics Statement}

Ethics approval for this study was obtained from the Human Research Ethics Committee at the Faculty of Health Sciences, University of Cape Town. For minors enrolled in the study, we obtained written informed consent from a parent or guardian. This consent procedure was approved by the Human Research Ethics Committee.

\section{Equations Used for Estimation of Transmission Risk}

The threshold for tuberculosis transmission was estimated using the carbon dioxide-based risk equation developed by Rudnick and Milton (refer to Figure 2 for descriptions of parameters) [13]. 


\begin{tabular}{|c|c|c|c|}
\hline Parameter & Description & Value & Range \\
\hline D & $\begin{array}{l}\text { Number of infections (effective contact } \\
\text { rate goal for TB control) }\end{array}$ & 7 & $(1-30)$ \\
\hline S & Number of susceptibles (n-1) & 30 & $(1-120)$ \\
\hline $\bar{f}$ & $\begin{array}{l}\text { Average fraction of indoor air that is } \\
\text { exhaled }\end{array}$ & Observed & -- \\
\hline $\bar{f}_{c}$ & $\begin{array}{l}\text { Critical rebreathed fraction for indoor } \\
\mathrm{CO}_{2} \text { concentration }\end{array}$ & $x$ & -- \\
\hline$I$ & Number of infectors & 1 & $1-2$ \\
\hline$q$ & Quantum generation rate & $3 q / h$ & $(1-13)$ \\
\hline$t$ & Total exposure time & $175 h$ & $(1-900)$ \\
\hline$n$ & Students per classroom & 31 & $(2-121)$ \\
\hline$Q$ & Ventilation rate (I/s per person) & $x$ & -- \\
\hline G & $\begin{array}{l}\text { Indoor } \mathrm{CO}_{2} \text { generation rate (I/s per } \\
\text { person) }\end{array}$ & Equation 6 & $\begin{array}{c}3800- \\
6460\end{array}$ \\
\hline$C_{\text {in }}$ & Indoor $\mathrm{CO}_{2}$ concentration (ppm) & Observed & $\begin{array}{l}(400- \\
6000)\end{array}$ \\
\hline$C_{\text {out }}$ & Outdoor $\mathrm{CO}_{2}$ concentration & 400ppm & -- \\
\hline $\bar{V}$ & $\begin{array}{l}\text { Average volume of gas exhaled for } \\
\text { adolescents }\end{array}$ & $\begin{array}{l}0.13 \mathrm{l} / \mathrm{s} \text { per } \\
\text { person }\end{array}$ & $0.1-0.17$ \\
\hline$C_{e x}$ & $\mathrm{CO}_{2}$ concentration in exhaled breath & $\begin{array}{l}38,000 \\
\mathrm{ppm}^{*}\end{array}$ & -- \\
\hline
\end{tabular}

Figure 2. Parameter definitions and values used in computing $\mathrm{CO}_{2}$ threshold and ventilation rates $[18-22,24,38-40] .{ }^{*} p p m(p a r t s$ per million) $=\mathrm{mg} / \mathrm{l}$

doi:10.1371/journal.pone.0096334.g002

$$
D / S=\left[1-\exp \left(-\frac{\bar{f} I q t}{n}\right)\right]
$$

The conversion between indoor $\mathrm{CO}_{2}$ concentration and ventilation rate is expressed by [17]

$$
Q=\frac{G}{C_{\text {in }}-C_{\text {out }}}
$$

The critical rebreathed fraction $\left(\bar{f}_{c}\right)$ represents the fraction of ambient $\mathrm{CO}_{2}$ under which a reduction in TB transmission would be expected to occur. Substituting $\left(\bar{f}_{c}\right)$ for the indoor $\mathrm{CO}_{2}$ concentration yields

$$
Q=\frac{G}{\bar{f}_{c}-C_{\text {out }}}
$$

The indoor $\mathrm{CO}_{2}$ generation rate is expressed by

$$
G=\bar{V} C_{e x}
$$

The ventilation rate can be converted to air changes per hour (ACH) by

$$
A C H=\frac{3600 Q n}{v o l}
$$

\section{Data Collection Procedures}

Using portable carbon dioxide detection devices (EasyView 80 $\mathrm{CO}_{2}$ analyzer, Extech Instruments, Waltham, MA) and custom monitors (based on COZIR Ambient sensors, Gas Sensing Solutions Ltd., Glasgow, UK), we monitored $\mathrm{CO}_{2}$ in nonmechanically ventilated classrooms in a high $\mathrm{TB}$ burden community under varying natural conditions. The accuracy of $\mathrm{CO}_{2}$ measurements taken by the sensor is reported by the factory to be $\pm 50 \mathrm{ppm}$ or $3 \%$ of each reading (www.cozir.com). To verify that devices were not affected by the wearer's respiration, we conducted an experiment measuring $\mathrm{CO}_{2}$ levels in an unventilated space with one individual using $\mathrm{CO}_{2}$ devices, placed on areas of the body where our study participants wore their devices. From these trials, we were not able to find differences in data from monitors hung from a neck lanyard or monitors worn in waist pockets - the two locations where subjects were instructed to keep the devices on their person.

Our sample consisted of 64 students carrying individual monitors over 91 school days throughout an entire school year (for a total of 509 hours of school time). The monitors provide a $\mathrm{CO}_{2}$ measurement in parts per million (ppm) every 60 seconds as well as GPS locations. The average number of students per class $(n)$ was 31. We estimated $q$ using the value obtained in previous studies [18-22] combined with the logic that - since the molecular epidemiology of TB in Cape Town militates against the presence of super-spreaders [23] $-q$ would not be at the high levels found in some hospital outbreaks. We also assumed that infectious cases would overlap with the same individuals for up to 175 hours of class time (i.e., 35 school days [24] at 5 indoor hours per day) before diagnosis. We then solved for the critical rebreathed fraction $\left(\bar{f}_{c}\right)$. 


\section{Solving for the Critical Rebreathed Fraction}

We calculated that the effective contact number per case must be reduced to $<14$ to reduce the current $\mathrm{TB}$ burden (see introduction). Since 50\% of transmission for 15-19 year-olds occurs in schools [25], the effective contact number for schools is

$$
14 * 0 \cdot 5=7
$$

(i.e., the portion of contacts in a TB case's total social-network that he/she infects in school). Setting $\mathrm{D}=7$ for 30 susceptibles (Equation 1) and solving for the critical rebreathed fraction $\left(\bar{f}_{c}\right)$ yields

$$
\bar{f}_{c}=\frac{0.266 n}{q t}
$$

\section{Results}

By substituting the values in Figure 2, we obtain a critical rebreathed fraction $\left(\bar{f}_{c}\right)$ of $1 \cdot 6 \%$, which correlates with an indoor $\mathrm{CO}_{2}$ concentration of $1000 \mathrm{ppm}$. Entering this value into equation 3 yields a ventilation rate of $8.6 \mathrm{l} / \mathrm{s}$ per person. Note that classes are more likely to approach steady-state conditions when highly ventilated.

Using equation 5 , the value $8.6 \mathrm{l} / \mathrm{s}$ per person (with an average class size of 31 students and class volume of 180,000 liters or $180 \mathrm{~m}^{3}$ ) [26] converts to between 5 and 6 air changes per hour $(\mathrm{ACH})$, which is around half the level of ventilation recommended for health care settings $[27,28]$.

To explore the ramifications of our recommendations in the local context, we conducted $\mathrm{CO}_{2}$ analyses in classrooms in an area of high TB prevalence in Cape Town, South Africa. Our findings demonstrate that students spend $60 \cdot 2 \%$ of their time above our recommended threshold (Figure 3 ).

A sample student day with $\mathrm{CO}_{2}$ measurements and GPS locations is presented in Figure 4. Visits to different classrooms and outside locations throughout the day are clearly identifiable. In addition, the $\mathrm{CO}_{2}$ environment encountered is seen to be highly variable. Classrooms $\mathrm{B}, \mathrm{H}$ and $\mathrm{G}$ achieve steady state conditions quite quickly. In spite of very high levels of $\mathrm{CO}_{2}$, classrooms $\mathrm{E}$ and $\mathrm{F}$ do not achieve steady-state conditions (these are the only classes visited without windows on more than one side of the room).

\section{Discussion}

In this article, we have presented a statistical buttressing of recommendations made over a century ago. It seems that - in an era of effective treatment - current TB prevention programs have become complacent in promoting the prevention benefits of ventilation. There is growing consensus that biomedical solutions will be insufficient to tackle the TB epidemic in low and middle income countries [29]. Thus, a renewed focus on environmental interventions is called for. Given the high smear positive rate of high-school adolescents in Cape Town informal settlements, the proposal to achieve $\mathrm{CO}_{2}$ levels of $1000 \mathrm{ppm}$ through natural ventilation (in the amount $12 \mathrm{ACH}$ for a standard classroom of $180 \mathrm{~m}^{3}$ ) will not only help achieve WHO guidelines for providing children with healthy indoor environments, it will also help curb the TB epidemic the 'old-fashioned way' (i.e., through improvements in air hygiene).

The cutoff of $1000 \mathrm{ppm}$ falls in line with regulations in other industrialized nations (Figure 5). It should be recognized that the benefits of increased ventilation are not limited to prevention of TB transmission: decreased respiratory illness, fewer school absences, and improved cognitive function have been demonstrated in the literature [30-32]. South Africa is not alone in failing to adequately ventilate schools (although the consequences may be greater due to the high TB incidence). The majority of European

Percent of time spent at various levels of $\mathrm{CO}_{2}$

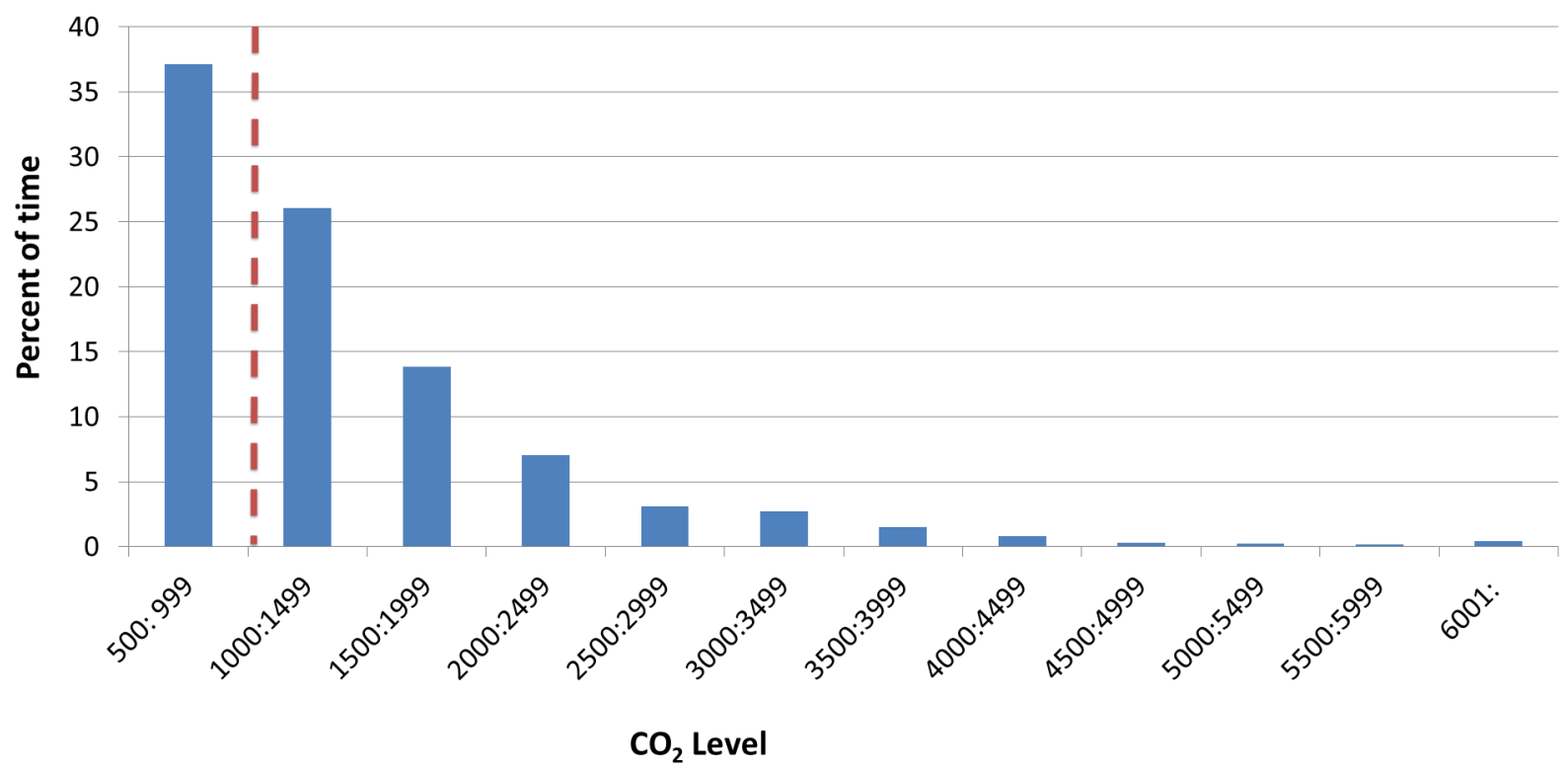

Figure 3. The percent of time spent at various levels of total $\mathrm{CO}_{\mathbf{2}}$ (in ppm). $\mathrm{CO}_{2}$ levels are shown in ranges of 500ppm. The dotted red line represents calculated threshold for reducing TB transmission. Sample: 64 students over 91 school days (509 class hours). doi:10.1371/journal.pone.0096334.g003 

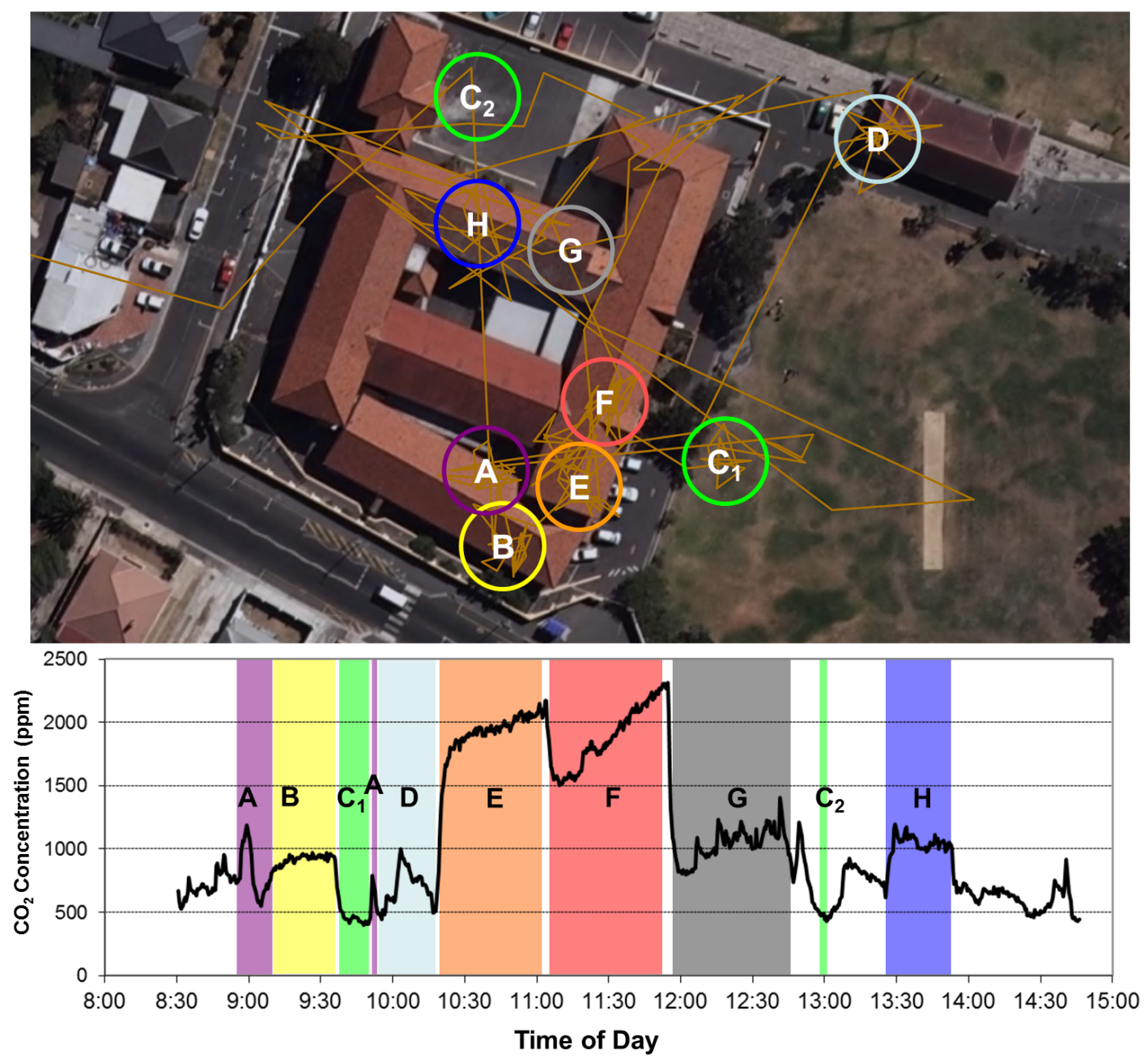

Figure 4. Sample student day with measured $\mathrm{CO}_{2}$ concentrations and GPS locations (A-H). doi:10.1371/journal.pone.0096334.g004

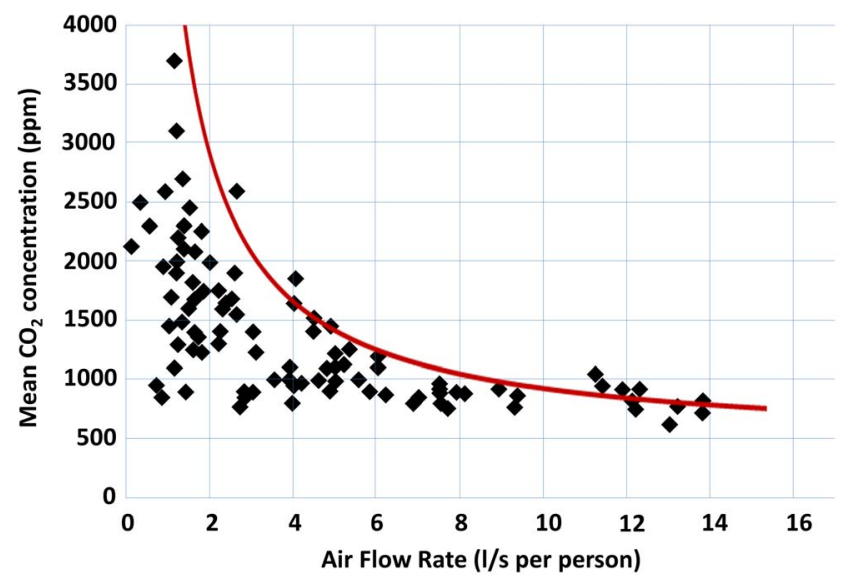

Figure 5. Recommended ventilation rates in classrooms by country [41-45]. ${ }^{*}$ Denotes calculated value. doi:10.1371/journal.pone.0096334.g005 


\begin{tabular}{|l|c|c|}
\hline \multicolumn{1}{|c|}{ Country } & $\begin{array}{c}\text { Ventilation rate } \\
\text { (l/s per person) }\end{array}$ & $\begin{array}{c}\text { Median peak } \mathbf{C O}_{2} \\
\text { concentration (ppm) }\end{array}$ \\
\hline Portugal & $8 \cdot 3$ & $1026^{*}$ \\
\hline Sweden & 8 & 1000 \\
\hline Netherlands & $5 \cdot 5$ & 1200 \\
\hline UK & 5 & 1100 \\
\hline USA & $7 \cdot 5$ & $\mathbf{1 0 0 0}$ \\
\hline Our proposal & $\mathbf{8 \cdot 6 *}$ & \\
\hline
\end{tabular}

Figure 6. Correlation between the mean indoor $\mathrm{CO}_{2}$ concentrations in naturally ventilated classrooms and the air flow (I/s per person). Red line represents relationship between air flow and mean $\mathrm{CO}_{2}$ concentration at steady state (defined by Equation 2). Adapted from $\mathrm{M}$. Santamouris et al. (2008) [33].

doi:10.1371/journal.pone.0096334.g006

classrooms in a meta-analysis by Santamouris et al., were found to be inadequately ventilated (see Figure 6) [33]. Furthermore, the occurrence of TB outbreaks in schools in middle- to high-income countries suggests a renewed focus on ventilation recommendations is apposite across a broad range of settings [34-36].

Given historic precedent, pharmacologic intervention on its own is unlikely to curtail the TB epidemic. This work would suggest that the addition of a key structural intervention such as improved school ventilation might enhance our efforts to effect TB control. Indeed, given the association of formal recommendations by Commissions on Ventilation with decreased TB notifications in industrialized nations [37], it may be prudent to revive such commissions in areas of high TB prevalence.

\section{Limitations}

1. We did not measure $\mathrm{CO}_{2}$ concentrations in a given classroom with multiple devices simultaneously and thus cannot provide an error analysis for our measurements; however, the devices were factory calibrated, and we periodically compared the performance

\section{References}

1. Dubos R, Dubos J (1952) The white plague: tuberculosis, man, and society. New Brunswick: Rutgers University Press.

2. Lienhardt C (2001) From exposure to disease: the role of environmental factors in susceptibility to and development of tuberculosis. Epidemiol Rev 23: 288-301.

3. Wood R, Lawn SD, Johnstone-Robertson S, Bekker L-G (2011) Tuberculosis control has failed in South Africa - time to reappraise strategy. SAMJ 101: 2009-2012.

4. World Health Organization (2013) Global Tuberculosis Report. Geneva. Available: http://www.who.int/tb/publications/global_report/en/.

5. Annual reports of the medical officer of health 1970-1985. Cape Town.

6. Van Niekerk L. Pocket Guide to South Africa 2011/12. Available: http://www. info.gov.za/aboutsa/housing.htm. Accessed 17 August 2013.

7. Engels F (1968) The condition of the working class in England. Stanford: Stanford University Press.

8. Johnstone-Robertson S, Lawn SD, Welte A, Bekker L, Wood R (2011) Tuberculosis in a South African prison - a transmission modelling analysis. SAMJ 101: 809-813.

9. Statistics South Africa (2011). Available: http://beta2.statssa.gov.za/.Accessed 3 December 2013.

10. Wood R, Racow K, Bekker L-G, Morrow C, Middelkoop K, et al. (2012) Indoor social networks in a South African township: potential contribution of location to tuberculosis transmission. PLoS One 7: e39246. doi:10.1371/journal.pone.0039246.

11. Middelkoop K, Bekker L-G, Liang H, Aquino LDH, Sebastian E, et al. (2011) Force of tuberculosis infection among adolescents in a high HIV and TB of monitors (in our offices) and found them to be consistently measuring within $10 \%$ of each other.

2. We did not record temperature so do not have temperature associations with the varying $\mathrm{CO}_{2}$ levels found in classrooms; however, we did conduct the study over a full year and thus control for the effect of a whole year's weather on classroom ventilation (i.e., number of windows open).

3. As shown in Figure 2, there is significant variation in the parameters used to determine the TB risk threshold; however, we feel that the use of empirically derived numbers for a highincidence community coupled with conservative choices for the theoretical parameters allows us to calculate a threshold for tuberculosis transmission that is evidence-based as well as practically meaningful.

\section{Author Contributions}

Conceived and designed the experiments: RW. Performed the experiments: ETR CDM DBK LGB RW. Analyzed the data: ETR CDM DBK LGB RW. Contributed reagents/materials/analysis tools: RW. Wrote the paper: ETR.

prevalence community: a cross-sectional observation study. BMC Infect Dis 11: 156. doi:10.1186/1471-2334-11-156.

12. Wells WF (1955) Airborne Contagion and Air Hygiene: An Ecological Study of Droplet Infections. Boston: Harvard University Press.

13. Rudnick S, Milton D (2003) Risk of indoor airborne infection transmission estimated from carbon dioxide concentration. Indoor Air 13: 237-245.

14. Riley E, Murphy G, Riley R (1978) Airborne spread of measels in a suburban elementary school. Am J Epidemiol 107: 421-432.

15. Lygizos M, Shenoi SV, Brooks RP, Bhushan A, Brust JCM, et al. (2013) Natural ventilation reduces high TB transmission risk in traditional homes in rural KwaZulu-Natal, South Africa. BMC Infect Dis 13. doi:10.1186/1471-2334-13300 .

16. Escombe AR, Oeser CC, Gilman RH, Navincopa M, Ticona E, et al. (2007) Natural ventilation for the prevention of airborne contagion. PLoS Med 4: e68. doi:10.1371/journal.pmed.0040068.

17. Persily A (1997) Evalutating building IAQ and ventilation with indoor carbon dioxide. ASHRAE Transactions 103: 193-204.

18. Riley R, Wells W, Mills C, Nyka W, McLean R (1957) Air hygiene in tuberculosis: quantitative studies of infectivity and control in a pilot ward. Am Rev Tuberc 75: 420-431.

19. Nardell E, Keegan J, Cheney S, Etkind S (1991) Airborne infection. Theoretical limits of protection achievable by building ventilation. Am Rev Respir Dis 144: 302-306. doi:10.1164/ajrccm/144.2.302.

20. Noakes C, Sleigh P (2009) Mathematical models for assessing the role of airflow on the risk of airborne infection in hospital wards. J R Soc Interface 6 Suppl 6: S791-800. doi:10.1098/rsif.2009.0305.focus. 
21. Furuya H, Nagamine M, Watanabe T (2009) Use of a mathematical model to estimate tuberculosis transmission risk in an Internet café. Environ Health Prev Med 14: 96-102. doi:10.1007/s12199-008-0062-9.

22. Wood R, Johnstone-Robertson S, Uys P, Hargrove J, Middelkoop K, et al. (2010) Tuberculosis transmission to young children in a South African community: modeling household and community infection risks. Clin Infect Dis 51: 401-408. doi:10.1086/655129.

23. Middelkoop K, Bekker L-G, Mathema B, Shashkina E, Kurepina N, et al. (2009) Molecular epidemiology of Mycobacterium tuberculosis in a South African community with high HIV prevalence. J Infect Dis 200: 1207-1211. doi:10.1086/605930.

24. Meintjes G, Schoeman H, Morroni C, Wilson D, Maartens G (2008) Patient and provider delay in tuberculosis suspects from communities with a high HIV prevalence in South Africa: a cross-sectional study. BMC Infect Dis 8: 72. doi:10.1186/1471-2334-8-72.

25. Andrews JR, Morrow C, Walensky RP, Wood R (2014) Integrating social contact and environmental data in evaluating tuberculosis transmission in a South African township. J Infect Dis: [Epub ahead of print]. doi:10.1093/infdis/ jiu 138.

26. South Africa Department of Basic Education (2011) Infrastructure Report. Pretoria.

27. Jensen PA, Lambert LA, Iademarco MF, Ridzon R (2005) Guidelines for preventing the transmission of Mycobacterium tuberculosis in health-care settings, 2005. MMWR Recomm Rep 54: 1-141.

28. World Health Organization (2009) WHO policy on TB infection control in health-care facilities, congregate settings and households. Geneva.

29. Hargreaves JR, Boccia D, Evans CA, Adato M, Petticrew M, et al. (2011) The social determinants of tuberculosis: from evidence to action. Am J Public Health 101: 654-662. doi:10.2105/AJPH.2010.199505.

30. Simpson JV (1923) A Report on the Ventilation of Schools. Journal of Hygiene 22: $164-174$.

31. Mendell MJ, Eliseeva EA, Davies MM, Spears M, Lobscheid A, et al. (2013) Association of classroom ventilation with reduced illness absence: a prospective study in California elementary schools. Indoor Air. doi:10.1111/ina.12042.

32. Satish U, Mendell MJ, Shekhar K, Hotchi T, Sullivan D, et al. (2012) Is CO2 an Indoor Pollutant? Direct Effects of Low-to-Moderate CO2 Concentrations on
Human Decision-Making Performance. Environmental Health Perspectives 120: 1671-1677.

33. Santamouris M, Synnefa A, Asssimakopoulos M, Livada I, Pavlou K, et al. (2008) Experimental investigation of the air flow and indoor carbon dioxide concentration in classrooms with intermittent natural ventilation. Energy and Buildings 40: 1833-1843. doi:10.1016/j.enbuild.2008.04.002.

34. Faccini M, Codecasa LR, Ciconali G, Cammarata S, Borriello GR, et al. (2013) Tuberculosis outbreak in a primary school, Milan, Italy. Emerg Infect Dis 19: 485-487. doi:10.3201/eid1902.120527.

35. Chen W, Xia Y, Li X, Zhou L, Li C, et al. (2012) A tuberculosis outbreak among senior high school students in China in 2011. J Int Med Res 40: 1830-1839.

36. Phillips L, Carlile J, Smith D (2004) Epidemiology of a tuberculosis outbreak in a rural Missouri high school. Pediatrics 113: e514-9.

37. New York State Commission on Ventilation (1923) Report of the New York State Commission on Ventilation. New York: E.P. Dutton and Company.

38. Tans P, Keeling R (2014) Global Greenhouse Gas Reference Network - Trends in Atmospheric Carbon Dioxide. NOAA/ESRL. Available: http://www.esrl. noaa.gov/gmd/ccgg/trends/global.html. Accessed 12 April 2014.

39. Feher JJ (2012) Quantitative Human Physiology: An Introduction. London: Academic Press.

40. Morawska L, Bofinger ND, Maroni M (1995) Indoor air: an integrated approach. Oxford: Pergamon.

41. Conceição EZE, Lúcio MMJR (2006) Air Quality Inside a School Building: Air Exchange Monitoring, Evolution of Carbon Dioxide and Assessment of Ventilation Strategies. International Journal of Ventilation 5: 259-270.

42. Geelen LMJ, Huijbregts MAJ, Ragas AMJ, Bretveld RW, Jans HWA, et al. (2008) Comparing the effectiveness of interventions to improve ventilation behavior in primary schools. Indoor Air 18: 416-424.

43. Smedje G, Norback D (2000) New Ventilation Systems at Select Schools in Sweden - Effects on Asthma and Exposure. Archives of Environmental Health 55: $18-25$.

44. Deparmtent for Education and Skills (DfES) (2006) Building Bulletin 101 Ventilation of School Buildings. London, UK.

45. American Society of Heating R and A-CE (ASHRAE) (2010) ANSI/ASHRAE Standard 62.1-2010: Ventilation for Acceptable Indoor Air Quality. Atlanta, USA. 